\title{
Política educacional e planejamento participativo: a experiência dos fóruns itinerantes de educação em Pernambuco
}

\author{
Education policy and participatory planning: \\ the experience of the itinerant education forums in Pernambuco \\ Política educacional y planeamiento participativo: \\ la experiencia de los fóruns itinerantes de educación en Pernambuco
}

\begin{abstract}
MÁrCia ANGELA DA SILVA AGUIAR*
$\diamond$

RESUMO - À luz do debate sobre a educação escolar como um direito social básico, e da escola como um espaço de formação e exercício de cidadania, o texto analisa o processo participativo de construção do plano estadual de educação de Pernambuco, no período de 1987 a 1990. Tal processo envolveu as municipalidades e setores organizados da sociedade política e da sociedade civil na busca do estabelecimento de uma política educacional capaz de favorecer a elevação do padrão de escolaridade da população e de contribuir para a instauração de formas colegiadas de gestão no sistema de ensino e nas escolas estaduais. $\mathrm{O}$ texto ressalta aspectos relevantes desta experiência que demarcam com nitidez as diferenças entre as formas de gestão escolar numa perspectiva democrática e aquelas que se pautam no ideário da competitividade e do ranqueamento entre as unidades escolares e as redes de ensino.
\end{abstract}

Palavras-chave - Políticas educacionais. Gestão da educação. Planejamento educacional.

\begin{abstract}
In light of the debate on school education as a basic social right and the school as a space of education and exercise of citizenship, the paper examines the participatory process of construction of the education plan of the State of Pernambuco between 1987-1990. This process involved the municipalities and organized sectors of political and civil societies aiming the formation of an education policy capable to favor the increase of the schooling standard of the population and contribute to the establishment of collegial democratic management in the education system and in state schools. The text analyses important aspects of this experience clarifying the differences between the forms of democratic school management and those which are based on the ideology of competitiveness and ranking.
\end{abstract}

Keywords - Educational policies. Education management. Educational planning.

RESUMEN - A la luz del debate sobre la educación escolar como un derecho social básico, y de la escuela como un espacio de formación y de ejercicio de ciudadanía, el texto analiza el proceso participativo de construcción del plan decenal de educación del estado de Pernambuco (Brasil), el período de 1987 a 1999. Tal proceso ha involucrado las municipalidades y sectores organizados de la sociedad política y de la sociedad civil en la búsqueda del establecimiento de una política educacional capaz de favorecer la elevación del patrón de escolaridad de la población y de contribuir para la instauración de formas colegiadas de gestión en el sistema de enseñanza y en las escuelas estaduales. El texto enfatiza aspectos relevantes de esta experiencia que demarcan con nitidez las diferencias entre las formas de gestión educacional en una perspectiva democrática y aquellas que se pautan en el ideario de la competencia y del ranqueamiento entre las unidades escolares y las redes de enseñanza.

Palabras clave - Políticas educacionales. Gestión de la educación. Planeamiento educacional.

\footnotetext{
* Doutora em Educação pela Universidade de São Paulo (São Paulo, SP, Brasil) e Professora na Universidade Federal de Pernambuco (Recife, PE, Brasil). E-mail:<marcia_angela@uol.com.br>.
} 


\section{INTRODUÇÃO}

Uma das conquistas da sociedade civil no período pós-ditadura no Brasil foi a retomada do debate nacional sobre a educação como um direito de cidadania, tal como ocorria em vários países da América Latina. Intensificou-se a produção científica na pós-graduação, trazendo aportes críticos ao campo educacional; retomou-se a análise crítica dos problemas educacionais e ampliou-se o protagonismo da sociedade civil neste campo. A sociedade brasileira reencontrava o caminho da participação política na luta pela ampliação dos direitos sociais que iriam ser consagrados na Constituição Federal de 1988.

Embora a década de 1980 tenha ficado conhecida como a década perdida no âmbito da economia, do ponto de vista político o retorno à normalidade democrática possibilitou a reorganização do movimento social em patamar inédito, com a emergência e afirmação de entidades e partidos populares, o fortalecimento dos sindicatos e a promulgação da Constituição da República Federativa do Brasil, em 1988 (BRASIL, 1988). A crise econômica, evidenciada pela alta inflacionária e a perda de poder aquisitivo da população, com a queda do emprego e a retração da renda, provocou grandes mobilizações sociais por eleições diretas para presidente da República, que se anunciavam mediante a emenda do deputado Dante de Oliveira (PMDB-MT), em abril de 1984. Como destaca Marangoni (2012, p. 61)

O país foi tomado de norte a sul por maciços atos de protesto...[...] Apesar de a emenda não ter sido aprovada, as mobilizações prosseguiram em greves gerais, inúmeras paralisações localizadas e na grande pressão para a aprovação de emendas populares algo inédito - na Constituinte, instalada em 1987. A oposição, capitaneada pelo PMDB, conseguiu eleger Tancredo Neves de forma indireta, no Colégio Eleitoral. No entanto, o novo presidente viria a falecer dias antes da posse. No início de 1985, seu vice, José Sarney, assume o governo. A situação econômica, com a disparada dos preços, era francamente desfavorável. Uma inflação mensal de $15 \%$ e impasses nas negociações da dívida externa marcam o período, que culmina com uma moratória no início de 1986. Aquela conjuntura foi também marcada pela adoção do primeiro plano heterodoxo de combate à inflação, o Cruzado, que congelava preços e salários a partir de fevereiro de 1986. A abrupta queda de inflação repercutiu fortemente nas eleições para governadores naquele ano. O PMDB, partido da situação, elegeu governadores em 22 dos 23 estados brasileiros.

Tal clima instaurou as condições para o estabelecimento de compromissos, de parte de vários governos subnacionais, que faziam oposição ao regime autoritário no sentido de instituir instâncias de ausculta para viabilizar a participação de setores sociais na formulação e operacionalização das políticas e ações de governo, inclusive no setor educacional. As lutas e mobilizações da sociedade civil pela ampliação dos direitos sociais alargavam os espaços de participação democrática e exigiam dos governos novos métodos de planejamento e gestão da máquina pública.

Deste modo, governos consagrados pelas urnas buscavam imprimir formatos democráticos aos processos de planejamento e gestão do aparato burocrático-administrativo em vários estados e municípios, constituindo-se, no campo educacional, o Congresso Mineiro da Educação (RODRIGUES, 1985) como uma das principais referências. Este Congresso, coordenado por Neidson Rodrigues, Superintendente da Secretaria de Educação de Minas Gerais, foi realizado em 1983 e congregou um contingente expressivo de educadores das escolas públicas estaduais e das instituições de ensino superior. Estruturado em quatro etapas: Encontros Municipais; Assembleia Municipal; Encontros Regionais e Encontros Municipais, o Congresso produziu o documento denominado Diretrizes para a Política de Educação de Minas Gerais (1983), base para a elaboração do Plano Mineiro de Educação 1984/87.

Reconhecido nos meios educacionais como uma experiência bem sucedida de planejamento educacional participativo, o Congresso Mineiro da Educação tornouse um incentivo para iniciativas similares da parte de alguns governos eleitos em 1982, como os de São Paulo e Paraná. Estavam em pauta, portanto, novas iniciativas concernentes às relações entre governo e sociedade civil, assentadas em princípios democráticos que se configuraram na Carta Magna de 1988.

Nessas experiências de gestão, predominava o ideário democrático de ampliação do acesso da população à escola pública de qualidade, demanda presente, sobretudo, no âmbito do movimento dos educadores, que organizaram as várias edições da Conferência Brasileira de Educação - CBE, que ocorreram na década de 1980, em várias regiões do país. A maior preocupação dos governos eleitos em 1982 era garantir a oferta de educação básica com qualidade, considerando que o Brasil ostentava um dos últimos lugares neste quesito diante de nações mais desenvolvidas.

$\mathrm{Na}$ verdade, até a década de 1980, a sociedade demandava do poder público acesso à escola, o que impulsionou a expansão da escolarização, mas sem muita atenção ao padrão de qualidade a ser ofertado por estas instituições. Este fato ocorre, como afirmam Oliveira e Araújo (2005), porque 
a demanda pela ampliação de vagas era muito mais forte do que a reflexão sobre a forma que deveria assumir o processo educativo e as condições necessárias para a oferta de um ensino de qualidade. Foi a incorporação quase completa de todos à etapa obrigatória de escolarização que fez emergir o problema da qualidade em uma configuração inteiramente nova ( p. 7).

Com efeito, a busca da qualidade da educação passou, então, a ser incluída como um item relevante nos programas de governos em vários estados, como pode ser observado no estado de Pernambuco, a partir de 1986. Neste ano, foi eleito governador Miguel Arraes de Alencar, que representava um projeto político-social comprometido com os interesses e necessidades da maioria da população.

A eleição de Arraes, segundo Oliveira (2006, p. 268)

significou a ruptura da hegemonia política de um mesmo grupo partidário que, há quatro legislaturas, vinha se revezando no poder, em diferentes momentos históricos, que abrangem desde o período de maior autoritarismo (1971-1974) até o início da redemocratização do país (1983-1986).

Durante a disputa eleitoral para o executivo estadual, foram estabelecidas as prioridades de ações governamentais e, dentre estas, o regate de uma dívida social: o acesso à educação básica.

Explicitar as condições de operacionalização desta política constitui o objetivo deste artigo, que tem como foco principal examinar a forma como o processo de planejamento educacional foi conduzido pela Secretaria de Educação de Pernambuco, no período de 1987 a 1990, com a participação de setores da sociedade civil e da sociedade política.

O texto aborda alguns aspectos políticos da gestão da educação em Pernambuco, suas principais diretrizes e as contribuições dos Fóruns Itinerantes de Educação, como estratégia de planejamento educacional, finalizando com considerações a respeito das ações desenvolvidas pela gestão focalizada.

\section{O SENTIDO DO PLANEJAMENTO EDUCACIONAL}

É relevante destacar o lugar estratégico atribuído ao programa de governo que emergiu do período da disputa eleitoral que antecedeu a gestão do Governo Arraes (março de 1987 a março de 1990). Partia-se do pressuposto de que, no contexto do debate eleitoral, os candidatos que participavam da disputa seriam chamados a explicitar princípios, compromissos e objetivos traduzidos em um programa de governo. Este foi um momento de mobilização de vários segmentos sociais, que expressaram suas demandas e reivindicações e buscaram influenciar a formulação das políticas públicas e a ação governamental a ser empreendida no caso de sucesso nas urnas.

Com a vitória de Miguel Arraes de Alencar, a qualidade da educação básica foi inserida entre as prioridades da ação governamental, ao lado do fortalecimento da base econômica do Estado e do atendimento das necessidades básicas da população, conforme anunciado no programa de governo. Para assegurar a implementação das ações governamentais na Secretaria de Educação de Pernambuco, o governador Arraes convidaria, para titular da educação, a Professora Silke Weber, do quadro docente da UFPE, uma intelectual reconhecida na comunidade acadêmica.

Coube a Weber assegurar o cumprimento dos compromissos expressos no programa de governo, o que pode ser observado já no início da gestão, quando retoma a discussão das diretrizes educacionais que dariam uma indicação das ações a serem desenvolvidas, conforme segue:

as diretrizes formuladas no período eleitoral, ao enfatizarem o reconhecimento da educação como uma das instâncias de formação e exercício da cidadania (percebida esta última como uma conquista da luta quase secular da sociedade civil brasileira e do avanço do conhecimento sobre a situação educacional do país e do Estado) conduziam necessariamente a priorizar a educação básica (WEBER, 1991, p. 22).

Para analisar a política educacional vigente no Estado de Pernambuco, no período de 1987 a 1990, e o sentido que foi atribuído ao planejamento educacional, é necessário destacar qual a concepção de Estado que lhe dá suporte. De acordo com Weber (idem, ibidem),

A concepção que fundamentou o processo de formulação e gestão da política educacional foi a de que o Estado constitui, nas sociedades capitalistas, representante e gestor de interesses em confronto, e que governos podem eventualmente se opor a interesses dominantes na luta pela superação da exploração e dominação. Nesse sentido, no âmbito da democracia representativa, o governo pode atuar como instância temporal de direção de um projeto políticosocial mais amplo de mudança das relações sociais prevalentes, suscitando a participação da sociedade civil e de outros grupos sociais, na escolha das formas de concretização do projeto submetido a escrutínio popular e na avaliação e controle de sua intervenção.

Nesta perspectiva, o planejamento educacional se configurava como "instrumento de definição de 
prioridades e de indicação de caminhos" e, portanto, deveria "refletir as linhas gerais do projeto político que conseguiu afirmar-se no confronto entre forças sociais com interesses distintos e diversos" (PERNAMBUCO, 1988). Tal concepção contrapunha-se à visão tecnicista e reducionista de planejamento, que desconsiderava seus determinantes sócio-históricos.

Coerentemente com esta concepção de planejamento educacional, de cunho democrático, a gestão da Secretaria de Educação procurou estabelecer novos marcos para o processo de formulação do Plano Estadual de Educação (1988-1991), de modo que viabilizasse apreender, de forma direta, as demandas dos vários setores da população. Mas, diferentemente de Minas Gerais, a Secretaria de Educação não realizou um congresso para definir as suas prioridades educacionais, como acentua Weber (idem, p. 19-20):

Pelo contrário, optou por discutir os fundamentos das diretrizes educacionais formuladas durante a campanha eleitoral de 1986. Para tanto, socializou o debate nacional a respeito das questões educacionais, de ensino, de formação, aperfeiçoamento e carreira docente, financiamento, planejamento e gestão, através da realização de Fóruns Itinerantes de Educação nas sedes dos dezessete Departamentos Regionais de Educação (DERE), intermediados por fóruns temáticos, seminários, encontros, palestras, debates.

Os Fóruns Itinerantes de Educação foram instituídos como canais de interlocução, que permitiam apreender as aspirações e interesses da comunidade escolar e dos setores organizados da população e cotejá-las com as diretrizes educacionais que foram discutidas no período eleitoral e consolidadas no programa de governo. A nova gestão rompia, na prática, com a feição tecnicista do planejamento, substituindo-a por um padrão democrático de planejamento.

Por outro lado, como destaca Oliveira (1991, p. 107) ao tratar

o planejamento como instância de coordenação, articulação e sistematização de propostas politicamente construídas, a Secretaria por certo deu sua contribuição para desmistificar o planejamento como esfera apenas de regulação de procedimentos técnicos, dentro de cujos limites a complexa e dinâmica realidade sócioeducacional deveria ser enfeixada.

Com tal perspectiva, os Fóruns Itinerantes de Educação tornaram-se um instrumento privilegiado de acompanhamento e avaliação da execução do Plano Estadual de Educação, bem como espaços de debates de questões locais, regionais e nacionais. Coincidentemente, no Plano Nacional estava em discussão, naquele período, o capítulo da educação na Constituição Federal de 1988 e as propostas para a Lei de Diretrizes e Bases da Educação Nacional, o que ampliou a dimensão do debate sobre o Plano Estadual.

A análise das condições da educação no plano nacional levava os governos subnacionais que assumiram no período da redemocratização a definirem como objetivos prioritários da gestão a garantia do acesso e permanência na educação básica. Não foi diferente o que ocorreu em Pernambuco. Vale ressaltar que, em 1985, o Estado apresentava um déficit de atendimento escolar de mais de $10 \%$ da população urbana de 7 a 14 anos e de mais de $32 \%$ da população rural desta mesma faixa etária e de quase $32 \%$ de adultos analfabetos (PERNAMBUCO, 1988, p. 24). Neste contexto, acesso e permanência passaram a ser palavras-chave na definição das diretrizes de governo do período aqui enfocado.

À luz dessas diretrizes, a Secretaria de Educação buscou a adesão dos diversos segmentos sociais para a construção de um projeto educacional que tivesse como cerne uma proposta pedagógica para todo o Estado e que garantisse $o$

domínio dos instrumentos básicos indispensáveis para o acesso ao conhecimento sistematizado - leitura, escrita e cálculo -, da reflexão crítica sobre a prática pedagógica em curso, do estímulo a uma postura ativa de professores e alunos frente ao conhecimento e à realidade (idem, p. 37).

Tal proposta pedagógica deveria ser o referente para as decisões relativas à organização da rede escolar, à formação continuada dos professores e a outros aspectos da política educacional do Estado. Esta concepção de gestão, que situava o pedagógico como carro-chefe das demais ações da secretaria, era um indicador da mudança de foco da gestão, que subordinava o administrativo ao pedagógico distanciando-se, assim, da visão tecnocrática do planejamento educacional que predominara até então.

Os Fóruns Itinerantes de Educação revelavam-se, assim, como uma estratégia que poderia ser bem sucedida nos processos de interlocução com os diferentes segmentos sociais em todas as regiões do Estado, favorecendo a sua participação na construção do Plano Estadual de Educação/1988-1991, como será visto a seguir. Visavase, com esta estratégia, a constituição de espaços de participação da sociedade civil para a discussão pública das questões de educação, o que pode ser considerado um avanço no tocante aos processos de formulação de políticas educacionais nos estados federativos, naquela conjuntura política. 


\section{A CONTRIBUIÇÃO DOS FÓRUNS ITINERANTES DE EDUCAÇÃO PARA A FORMULAÇÃo dO PLANO ESTADUAL DE EDUCAÇÃO}

Os debates propiciados pela condução política da nova gestão da Secretaria de Educação validaram a tese de que a

a educação pública em Pernambuco consistia, principalmente, em um mecanismo de conservação do poder de forças políticas que, tendo se revezado no governo do Estado durante o regime militar, foram confirmadas eleitoralmente, através do casuísmo do voto vinculado, nas primeiras eleições governamentais após o golpe de Estado. E o que possuía menor importância era exatamente a tarefa de ministrar o ensino de primeiro e segundo graus, nos seus diversos tipos e modalidades (WEBER, 1991, p. 20).

Contrapondo-se a esta forma de tratar a educação no Estado, a Secretaria de Educação re-afirma as diretrizes de governo na condução de suas ações: a universalização da educação básica com qualidade, a dignificação do trabalho do educador e a democratização da gestão educacional. Tais diretrizes deram o norte para as discussões nos Fóruns Itinerantes de Educação, intermediados por outros mecanismos de participação social, tais como os fóruns temáticos, seminários e reuniões regionais. Aliás, os Fóruns Itinerantes temáticos, de caráter pedagógico, foram instituídos com o objetivo de dinamizar o debate das políticas de ensino referentes aos diversos níveis e modalidades e às políticas de formação de docentes, dentre outros temas.

Instaurava-se, desta forma, no sistema estadual de ensino, uma dinâmica de participação efetiva na definição e desenvolvimento da política educacional. Os debates ocorridos nos Fóruns Itinerantes, em especial o I e o II, sistematizados pelas equipes técnicas da Secretaria de Educação, constituíram conteúdos do Plano Estadual de Educação 1988-1991 (Pernambuco, 1988). O processo de discussão deste Plano teve início com a realização do I Fórum Itinerante de Educação, em maio de 1987, sob a coordenação dos Departamentos Regionais de Educação (DERE) e coordenação geral das instâncias de planejamento da Secretaria de Educação. No II Fórum Itinerante de Educação, realizado em todas as regiões do estado, nos meses de novembro e dezembro do mesmo ano, foram consolidadas as propostas de programas e metas do Plano. Vale ressaltar que

ambos os Fóruns, precedidos de diversas reuniões com municípios, entidades da sociedade civil, comunidade escolar, resultaram na realização de dezessete sessões amplas, ocorridas nas sedes dos DERE. De tais sessões participaram cerca de 20 mil pessoas, 156 dos 167 municípios do Estado, mais de 1600 escolas, além de representantes da sociedade política e de inúmeras organizações da sociedade civil (idem, p. 21).

Contudo, é importante mencionar que os intensos debates ocorridos nos Fóruns revelavam, também, as disputas existentes quanto à compreensão do tipo de participação no processo de elaboração do Plano Estadual de Educação proposto pela Secretaria de Educação. Os sindicatos, associações, entidades e a classe política não reconheciam as reuniões com os municípios e técnicos da secretaria como uma via relevante para influenciar a política educacional, como destaca Weber (idem, ibidem), referindo-se à orientação da Secretaria de Educação na condução da elaboração do plano estadual:

Entretanto, este tipo de participação, na elaboração do Plano, não correspondia aos anseios das entidades dos educadores, que tudo fizeram para transformar o caráter consultivo desses Fóruns em instâncias deliberativas, onde desejavam ver encaminhados assuntos polêmicos como escolha de direção de escolas e compra de vagas à rede privada de ensino.

É oportuno observar que a Secretaria de Educação procurava instaurar uma cultura democrática de planejamento e de gestão em um estado cuja prática administrativa tradicional era marcada pelo clientelismo e fisiologismo. Tal empreitada, obviamente, encontrava muitos obstáculos e desafios. Para dar uma ideia aproximada do tamanho das dificuldades encontradas pela gestão da Secretaria, mencione-se a decisão do governo, de redução

para menos de mil indicações de caráter político os quase seis mil cargos de confiança de diretores, vicediretores, secretários de escola, supervisores escolares, coordenadores de laboratórios de apoio didático e de núcleos de merenda escolar, tradicionalmente distribuídos entre correligionários (idem, p. 22).

Evidentemente, uma decisão deste teor feria interesses de vários segmentos, o que se refletia nas posturas de resistência evidenciadas ao longo do processo de participação nos Fóruns Itinerantes de Educação. Tais obstáculos, contudo, não impediram que os Fóruns Itinerantes contribuíssem com a definição de prioridades para o Plano Estadual de Educação.

Tendo como horizonte a construção de uma escola pública de qualidade, foram definidas prioridades para a materialização das três diretrizes propostas no programa de governo. A constatação de que persistiam altos índices de evasão nas redes estadual e municipal $(35,7 \%$ na 
passagem da $1^{\underline{a}}$ para a $2^{\underline{a}}$ série e de $47,1 \%$ na passagem da $4^{\mathrm{a}}$ para a $5^{\mathrm{a}}$ série da rede municipal), bem como o fato de a taxa de reprovação vir se mantendo constante $(28 \%$ e $29 \%$, na rede estadual, chegando a atingir quase $35 \%$ na $1^{\underline{a}}$ série) mostrava a necessidade de uma intervenção urgente para enfrentar os fatores intraescolares do fracasso escolar (idem, p. 22-23).

Todavia, uma ação efetiva para modificar tais índices requeria novos aportes financeiros, o que para o Estado de Pernambuco mostrava-se de difícil obtenção, tendo em vista a redução sistemática de recursos operada pelo executivo federal junto ao governo Arraes, conforme demonstra Antunes (1991) em artigo sobre o financiamento da educação pública, focalizando a atuação do governo de Pernambuco, entre 1987 e 1990. Como reitera Oliveira (2006, p. 272)

No cenário do Governo Sarney, marcado pelo clientelismo transmutado em discurso de descentralização, a destinação política dos recursos federais mostrou-se um obstáculo ao financiamento do Plano Estadual de Educação, que viria a ter, por essa razão, a sua execução bancada quase totalmente com recursos do Tesouro do Estado.

Reconhecendo as limitações financeiras, a gestão da Secretaria de Educação optou por desenvolver ações com recursos locais, mas que tivessem um efeito multiplicador para toda a rede pública de ensino, inclusive a rede municipal. Tratava-se de uma estratégia ousada, para enfrentar problemas educacionais de grande complexidade e materializar as três diretrizes de governo. Assim, impunham-se as seguintes prioridades:

a alfabetização efetiva dos alunos matriculados de 1a a 4a série da rede pública, de modo a estancar a produção de novos analfabetos; o aperfeiçoamento do corpo docente e a melhoria de suas condições de trabalho; a utilização de formas descentralizadas e desconcentradas de gestão, tornando orgânica à finalidade educativa a estrutura administrativa da Secretaria; e a busca de diálogo permanente com entidades da sociedade civil, ligadas ou não à educação, e com representantes da sociedade política, com vistas à avaliação e controle da gestão educacional (WEBER, 1991, p. 22).

Com base nessas prioridades, foram definidas as políticas para as diversas áreas e que se desdobraram nos dez programas do Plano Quadrienal de Ação do Plano Estadual de Educação/1998-1991. Neste contexto foram formuladas políticas de expansão e melhoria da rede pública escolar, melhoria do ensino, apoio ao estudante, dignificação do trabalho do educador, ampliação dos espaços educativo-culturais, articulação das redes públicas de ensino, democratização do processo de planejamento, coordenação e gestão, e aprofundamento do conhecimento da educação no Estado (idem).

Os programas, projetos e ações decorrentes deste posicionamento político da Secretaria de Educação foram implementados no Estado num clima de permanente debate, em que a busca de aperfeiçoamento individual e coletivo da prática pedagógica se fazia presente, num processo de ação-reflexão-ação (MENEZES, 2012).

\section{OS FÓRUNS ITINERANTES DE EDUCAÇÃO COMO ESPAÇOS DE ACOMPANHAMENTO E AVALIAÇÃO DA POLÍTICA EDUCACIONAL}

\section{A instituição dos Fóruns Itinerantes de Educação} como instrumentos de planejamento e gestão decorreu, sobretudo, da intenção da gestão da Secretaria de criar estruturas e formas colegiadas de trabalho, que possibilitassem a participação dos segmentos da população alijados do debate educacional. Cabiam, no modelo dos Fóruns Itinerantes de Educação, as dimensões de acompanhamento e avaliação da política educacional.

Por outro lado, como destaca Weber (idem, p. 39):

a escolha desse tipo de gestão colegiada da estrutura educacional estadual se fundamenta no seu caráter eminentemente pedagógico e participativo, cuja dinâmica necessariamente conduz à constituição de uma perspectiva de unidade de ação.

Para materializar tal intenção seria necessário uma ação articulada que requeria a formulação de uma visão de educação que se tornasse "referência comum, mínima, para os processos de análise e de decisão no tocante aos seculares problemas educacionais, bem como para o controle e avaliação das ações governamentais".

Ora, construir esta "visão comum" demandaria um grande esforço no sentido de estruturar,internamente, formas colegiadas de trabalho; submeter à crítica permanente as propostas e ações em curso e socializar tais ideias na rede pública de ensino, com os diferentes atores. Tratava-se, certamente, de experimentar formas de governar que substituíam a racionalidade técnica por uma visão política dos processos pedagógicos. Isto significava estabelecer os elos e conexões entre as diretrizes da plataforma de governo construída no período eleitoral e as ações pedagógicas oriundas das diretrizes estabelecidas, considerando a realidade socioeducacional, o avanço do conhecimento da área e a prática pedagógica da escola pública. No processo de discussão destes aspectos emergiam os limites e potencialidades da ação de governo em sua interação com a sociedade civil.

A construção processual desta referência comum tornaria possível discutir os parâmetros, bem como efetivar o acompanhamento e a avaliação da política 
educacional em curso no Estado. O início desta construção passaria pela instituição de formas colegiadas de gestão, na estrutura burocrática da Secretaria. Nesta perspectiva, foram criadas as várias instâncias colegiadas com a participação dos dirigentes da Secretaria - Colegiado de Diretoria, Colegiado Ampliado de Direção, Colegiado das distintas Diretorias e Departamentos, que passaram a ter a escola e a realidade socioeducacional como elementos centrais de sua reflexão. Esta dinâmica constituía uma etapa fundamental para assegurar a unidade de ação dos dirigentes em prol da qualidade da escola pública em todas as regiões do Estado.

A elaboração desta visão de educação demandava, de acordo com Weber (idem, p. 39),

a circulação e o processamento de informações e de posições tanto diferenciadas como diferentes e, igualmente, consciência do papel que a instância educacional vem desempenhando ao longo da história e do potencial transformador que contraditoriamente ela também contém. Ou seja, implicava ter presente, ao lado de sua dimensão pedagógica e técnica, a sua dimensão política: aparelho ideológico de Estado e instância de formação e exercício de cidadania.

Coerentemente com esta compreensão, o processo de elaboração do Plano Estadual de Educação conduzido pela Secretaria consolidou outra forma de planejar as ações educacionais. Introduzia-se, assim, em Pernambuco, um padrão democrático de planejamento, entendido como "processo político de definição de políticas públicas" (OLIVEIRA,1991, p. 104). Neste processo, os canais institucionais - Fóruns Itinerantes de Educação, Fóruns Temáticos, Reuniões Regionais, Seminários - mostraram-se eficazes para propiciar o debate das diretrizes educacionais, como também para favorecer o acompanhamento e avaliação das ações do governo.

O planejamento deixava, portanto, de ser visto como um conjunto de técnicas neutras, tendo em vista que a Secretaria conferia-lhe um conteúdo explícito ao vincular as atividades de planejamento ao projeto políticopedagógico, como afirma Oliveira (idem):

Esse caminho sinalizaria, assim, a quebra do enfoque de planejamento como tendo um fim em si mesmo, para o questionamento, no nível do corpo técnico, do formalismo e do ritualismo que cercavam aquela atividade no Órgão. Mas o importante é que, tratando o planejamento como instância de coordenação, articulação e sistematização de propostas politicamente construídas, a Secretaria por certo deu sua contribuição para desmistificar o planejamento como esfera apenas de regulação de procedimentos técnicos, dentro de cujos limites a complexa e dinâmica realidade sócioeducacional deveria ser enfeixada.
A ênfase na dimensão política e nos conteúdos educacionais do planejamento foi determinante para a adoção de novos padrões para o acompanhamento e avaliação das ações na rede. Nesta perspectiva, podem ser situados o Fórum Itinerante de Educação, os Fóruns Regionais Temáticos e as Reuniões com as equipes dirigentes da Secretaria em todos os níveis.

A Secretaria entendia que a integração entre as dimensões normativa e política do padrão democrático de planejamento adotado requeria a existência de uma instância de coordenação de todo o processo de planejamento, o que deveria ser assumido pelos órgãos colegiados de direção - Colegiado de Direção e Colegiado Ampliado de Direção, proposta que acarretaria mudanças importantes na estrutura organizacional da Secretaria. Tal processo significava reformar a estrutura administrativa do órgão, o que demandaria, da direção, enfrentar o desafio de efetivar tal mudança de forma democrática e de evitar a armadilha de instituir instâncias internas que reduzissem o papel dos colegiados e concentrassem o poder de decisão em relação à formulação e implementação das políticas educacionais.

Neste processo, os Fóruns Itinerantes de Educação foram considerados o principal instrumento de acompanhamento e avaliação da execução do Plano Estadual de Educação, ao lado de mecanismos tradicionais do planejamento. Como reitera Oliveira (idem, p. 107),

o privilégio dado à dimensão democrática e processual do planejamento, em detrimento dos aspectos normativos, não significou, entretanto, o descarte da recorrência a alguns mecanismos tradicionais como planilhas, relatórios, planos de aplicação de recursos financeiros, pois, como é sabido, o planejamento, enquanto instrumento de ação estatal, possui necessariamente uma dimensão reguladora, que requer mecanismos formais de expressão, a fim de dar conta, inclusive, das exigências de caráter legal e administrativo, concernentes ao próprio funcionamento da máquina governamental .

Ao longo do Governo Arraes, a Secretaria de Educação realizou quatro Fóruns, com 68 sessões e ampla participação dos segmentos sociais, cujos debates foram gravados e posteriormente transcritos e sistematizados pelas equipes técnicas, o que permitia aos gestores identificar e dar respostas às demandas apresentadas. Esta dinâmica, ao lado dos relatórios técnicos concernentes à execução dos programas e ações favoreceu, também, os processos de acompanhamento da execução do Plano, que recebiam aportes avaliativos das instâncias de direção da Secretaria.

Os Fóruns Itinerantes de Educação, canais de interlocução com os setores sociais e com as escolas, 
permitiram não só "a discussão da política educacional que se forjava e que logo se implantava" (VELLOSO, 1991, p. 9), como também demonstraram ser instâncias privilegiadas de acompanhamento e de avaliação das ações de governo em interação com a sociedade civil, no campo educacional. Dada a sua centralidade na construção participativa do plano estadual de educação, os fóruns suscitaram interesse acadêmico, o que se reflete em vários estudos que abordam a participação social no campo da educação (NUNES, 1993; SAMPAIO; FERREIRA, 1996; MONTEIRO DA SILVA, 1996; OLIVEIRA, 2006; MENEZES, 2012).

\section{CONSIDERAÇÕES FINAIS}

(Re)visitar as experiências dos sistemas de ensino que adotaram, em contextos e conjunturas específicas, formas democráticas de planejamento educacional pode fornecer aos atuais dirigentes e planejadores dos sistemas de ensino elementos teórico-práticos para reforçar ou inovar as práticas de formulação dos planos e programas governamentais, bem como ampliar as possibilidades de indução do debate social e educacional a respeito de questões atinentes à educação como direito social.

Neste sentido, a experiência da Secretaria de Educação de Pernambuco, no período de 1987 a 1990, devido às inovações que introduziu no que tange às concepções e práticas do planejamento e gestão, tendo como referência a luta pela qualidade da educação pública, constitui a demonstração da viabilidade de uma prática de gestão comprometida com a construção democrática da política educacional.

Um dos aspectos que chama a atenção na análise desta experiência é a busca de coerência entre os programas e ações desenvolvidos e as concepções de Estado e de educação assumidas de forma coletiva pela gestão da Secretaria. A gestão entendia que a formulação e desenvolvimento dos projetos e ações ocorriam num clima de disputa política, decorrente de visões diferenciadas a respeito da educação básica e da política educacional implementada. Daí a iniciativa de propor formas colegiadas de gestão, que propiciassem a condução das políticas, programas e ações num clima permanente de debate democrático.

A análise da forma de condução desta gestão certamente traz à tona elementos importantes para $o$ debate a respeito das diretrizes que a inspiraram e que, ainda hoje, continuam pertinentes às lutas em prol da educação pública: a universalização da educação básica com qualidade, a dignificação do trabalho do educador e a democratização da gestão educacional.

Os Fóruns Itinerantes de Educação, abertos à participação social, constituem o símbolo maior de um período em que, no estado de Pernambuco, foram instituídas, no contexto da luta pela afirmação do direito social à educação, as condições políticas que viabilizaram o desenvolvimento de uma política educacional comprometida com os ideais republicanos de uma educação de qualidade para todos e o exercício democrático da gestão da rede pública de ensino.

Reconhecer e avaliar as potencialidades, conquistas e limites desta experiência de gestão certamente contribui para ampliar o debate sobre os caminhos que se abrem para a formulação de políticas educacionais que levem em conta a participação social.

\section{REFERÊNCIAS}

ANTUNES, Ana Maria de Cerqueira. A propósito do financiamento da educação pública. In: WEBER, Silke (Org.). Democratização, educação e cidadania: caminho do Governo Arraes (1987-1990). São Paulo: Cortez, 1991. p.119-142.

BRASIL. Constituição da República Federativa do Brasil. Brasília: Senado Federal, 1988.

MARANGONI, Gilberto. Anos 1980, década perdida ou ganha? In: Desafios do Desenvolvimento, Brasília: IPEA, ano 10, n. 79, jun. 2009, p. 56-63. Disponível em: $<$ http:// www.ipea.gov.br/desafios/images/stories/PDFs/desafios072_ completa.pdf $>$.

MENEZES, Marília Gabriela. Contribuições de Paulo Freire para as políticas e práticas curriculares nos sistemas de ensino. 2012. Tese (Doutorado em Educação) - Universidade Federal de Pernambuco, Recife, 2012.

NUNES DA SILVA, Itamar. Democracia e cidadania: um estudo da relação política do Estado com a sociedade civil no Governo Popular de Pernambuco. O caso dos trabalhadores em educação. 1993. Dissertação (Mestrado em Ciência Política) - Universidade Federal de Pernambuco, Recife, 1993.

OLIVEIRA, Maria das Graças Corrêa de. Conteúdo do Planejamento: uma questão relevante. In: WEBER, Silke (Org.). Democratização, educação e cidadania: caminho do Governo Arraes (1987-1990). São Paulo: Cortez, 1991, p. 103-118.

OLIVEIRA, Maria das Graças Corrêa de et al. (Org.). Continuidades e Descontinuidades das políticas de educação básica: o caso de Pernambuco. Recife: Editora Universitária, UFPE, 2006.

PERNAMBUCO. Plano Estadual de Educação, 1988/1991. Coord. e redação - S. Weber, M. G. C. de Oliveira e M. A. S. Aguiar. Secretaria de Educação. Recife: Inojosa, 1988.

RODRIGUES, Neidson. Por uma nova escola - o transitório e o permanente na educação. São Paulo: Cortez; Autores Associados, 1985.

SAMPAIO, Maria Cristina Hennes; FERREIRA, Rosilda Arruda. Democratização, cidadania e transformações: as utopias do Governo Arraes. João Pessoa: UFPB: Universitária, Recife: UFPE: Universitária, 1996. 
SILVA, Angela Maria Monteiro da. Planejamento educacional e democratização: um estudo dos fóruns itinerantes de educação em Pernambuco no Governo Arraes (1987-1990). 1996. Dissertação (Mestrado em Educação) - Universidade Federal de Pernambuco, Recife, 1996.

WEBER, Silke (Org.). Democratização, educação e cidadania: caminho do Governo Arraes (1987-1990). São Paulo: Cortez, 1991.
VELlOSO, Jacques. Prefácio. In: WEBER, Silke (Org.). Democratização, educação e cidadania: caminho do Governo Arraes (1987-1990). São Paulo: Cortez, 1991. p. 7-12.

Artigo recebido em janeiro 2014. Aprovado em junho 2014 